\title{
Estimativa do Estoque de Biomassa em um Fragmento Florestal Usando Imagens Orbitais
}

\author{
Antonio Santana Ferraz ${ }^{1}$, Vicente Paulo Soares ${ }^{2}$, Carlos Pedro Boechat Soares ${ }^{2}$, \\ Carlos Antônio Alvares Soares Ribeiro ${ }^{2}$, Daniel Henrique Breda Binoti², \\ Hélio Garcia Leite ${ }^{2}$
}

${ }^{1}$ Departamento de Engenharia Civil, Universidade Federal de Viçosa - UFV, Viçosa/MG, Brasil ${ }^{2}$ Departamento de Engenharia Florestal, Universidade Federal de Viçosa - UFV, Viçosa/MG, Brasil

\begin{abstract}
RESUMO
Este trabalho teve como objetivo estimar a biomassa aérea de um fragmento de Floresta Estacional Semidecidual, situada no município de Viçosa-MG, através de imagens ortorretificadas do satélite IKONOS. Com base em dados de inventário florestal, conduzido em 15 parcelas de $1000 \mathrm{~m}^{2}(20 \mathrm{~m} \times 50 \mathrm{~m})$, foram obtidas as estimativas dos estoques de biomassa aérea, a partir de equações alométricas. Estas estimativas foram relacionadas com variáveis digitais (reflectância nas quatro bandas multiespectrais e em 12 índices de vegetação), extraídas das imagens digitais, empregando-se Redes Neurais Artificiais (RNA). Os resultados mostraram que, para as condições da área de estudo, o emprego da técnica de RNA com apenas as bandas 1, 2, 3 e 4 do satélite IKONOS como variáveis de entrada foi eficiente para estimar a biomassa aérea total, embora os resíduos tenham sido ainda menores quando foram utilizadas as quatro bandas e os 12 índices de vegetação.
\end{abstract}

Palavras-chave: sensoriamento remoto, parâmetro biofísico, floresta estacional semidecidual.

\section{Biomass Stock Estimate in a Forest Fragment Using Orbital Data}

\begin{abstract}
The objective of this study was to use a set of orthorectified IKONOS satellite data to estimate aerial biomass in a semideciduous seasonal forest fragment located in Viçosa, state of Minas Gerais, Brazil. Estimates of above ground biomass were obtained with allometric equations based on forest inventory data conducted in fifteen $1,000 \mathrm{~m}^{2}(20 \mathrm{~m} \times 50 \mathrm{~m})$ parcels. These estimates were related to digital variables (reflectance of four spectral bands and 12 vegetation indices) extracted from digital images using Artificial Neural Network (ANN). The results showed that for the conditions of the study area, the use of ANN with only bands 1, 2, 3 and 4 of the IKONOS satellite as input variables was efficient to estimate the total aerial biomass, although the residual was even lower when 4 bands and 12 vegetation indices were used.
\end{abstract}

Keywords: remote sensing, biophysical parameter, semideciduous forest. 
$179-8087.052213$

0980 (impresso $)^{1 . ~ I N T R O D U C ̧ A ̃ O ~}$

79-8087 (online)

Os estudos de quantificação de biomassa em florestas têm sido realizados por meio de métodos diretos e indiretos. Diferentes técnicas relacionadas a estimativas de biomassa envolvendo o método direto são encontradas na literatura. Descrições de algumas destas técnicas, como a técnica do corte estratificado (stratified clip technique), o método da árvore média (mean tree method) e o método da parcela, são apresentadas por Silveira et al. (2008). Dentre outros trabalhos envolvendo o método direto, citam-se os de Higuchi \& Carvalho Júnior (1994) e Watzlawick (2003).

Já os métodos indiretos são baseados na correlação da biomassa com alguma variável obtida por medição no campo, sem necessidade de abate da árvore. Estas estimativas podem ser feitas a partir de relacionamentos empíricos entre a biomassa e outras variáveis mais facilmente mensuradas no povoamento, como o Diâmetro à Altura do Peito (DAP); pode-se partir também de uma base de dados de um Sistema de Informações Geográficas (SIG), construída a partir de um inventário florestal, ou ainda através de imagens orbitais do povoamento, utilizando-se das técnicas do Sensoriamento Remoto (Ferraz, 2012).

Segundo Somogyi et al. (2006), as estimativas de biomassa para grandes áreas florestais têm sido obtidas de forma indireta, com base em informações originárias de inventário florestal. Equações de biomassa são utilizadas para transformar dados de altura, diâmetro e volume em estimativas de biomassa.

Nos últimos anos, com a disponibilidade de imagens de alta resolução, provenientes de sensores remotos, e com os avanços nas técnicas de processamento digital destas imagens, o sensoriamento remoto tem sido utilizado para estudos relacionados à estimativa de biomassa florestal, com base na associação do conteúdo de biomassa com os valores de radiância/reflectância, obtidos com a utilização de imagens de satélite (Watzlawick et al., 2009).
Normalmente, estas estimativas são efetuadas com a utilização dos chamados índices de vegetação (IVs) e de outras variáveis extraídas de imagens de sensoriamento remoto, apresentando a grande vantagem de proporcionar a acessibilidade de informações em locais remotos de difícil acesso, além de ser menos oneroso, em termos de trabalhos de campo, quando comparado aos métodos tradicionais.

A análise comparativa entre os resultados relacionados à quantificação da biomassa obtidos por meio de técnicas de sensoriamento remoto, aqueles oriundos das técnicas tradicionais, é facilitada, quando envolve o caso de florestas plantadas, por estas serem normalmente constituídas de apenas um gênero e periodicamente inventariadas (Silveira et al., 2008).

Entretanto, no caso de florestas naturais, normalmente heterogêneas, com grande diversidade florística, fisionômica e fenológica, a utilização desta técnica reveste-se de maior complexidade, uma vez que há pouca disponibilidade de dados quantitativos de biomassa coletados em nível de campo (Souza \& Ponzoni, 1998). Desta forma, há carência de pesquisas que integrem dados de diferentes escalas e fontes, como inventários florestais e imagens de satélites, para a obtenção de mapas de distribuição de dados biofísicos para florestas naturais (Schoeninger, 2008b).

Diante do exposto, este trabalho teve como objetivo estimar a biomassa aérea de um povoamento inequiâneo, utilizando dados de sensoriamento remoto.

\section{MATERIAL E MÉTODOS}

\subsection{Caracterização da área de estudo}

O trabalho foi realizado em um fragmento florestal de mata nativa, classificado como Floresta Estacional Semidecidual Montana, localizado no município de Viçosa-MG, no campus da Universidade Federal de Viçosa (UFV) (Figura 1). Este fragmento está inserido em uma área denominada de 'Mata da Silvicultura', com cerca de 17 hectares, adquirida 

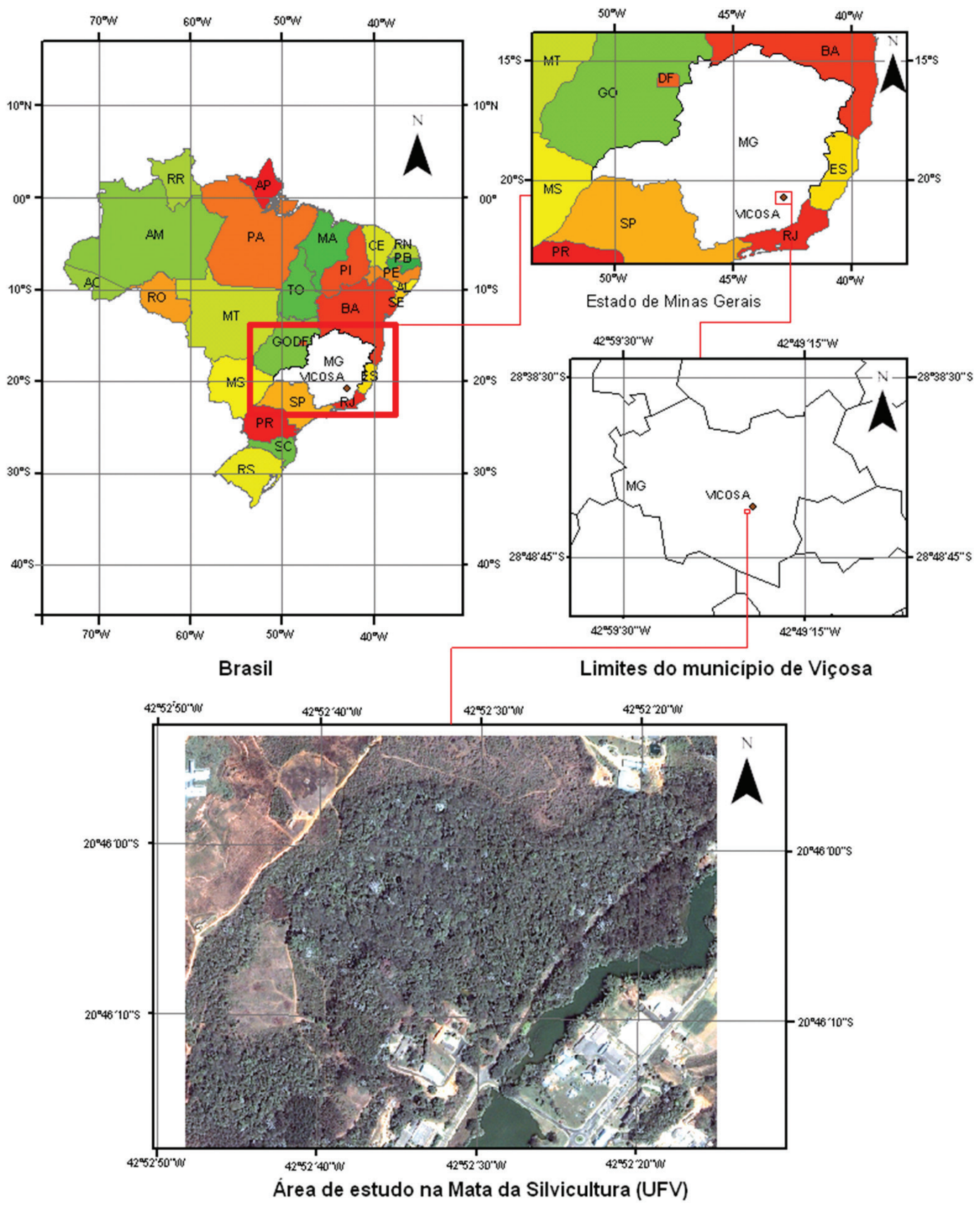

Coordenadas no Sistema Geodé sico WGS84

Figura 1. Localização da área de estudo.

Figure 1. Study area location.

pela UFV em 1936 e, desde então, é protegida contra cortes e extração de madeira (Flores, 1993).

Em termos pedológicos, na região há predominância de Latossolos Vermelho-Amarelo Distróficos típicos e Cambissolos HáplicosTb
Distróficos latossólicos (Rezende, 1971; Embrapa, 2006).

O clima da região de Viçosa está classificado, segundo Köppen, como Cwb, com verões chuvosos e invernos secos (Romanovski, 2001). A topografia na 
área de estudos é acidentada, com relevo fortemente ondulado e com altitudes variando de 650 a 750 metros.

\subsection{Análise dos dados}

\subsubsection{Inventário da biomassa aérea}

Amaro (2010) realizou um inventário florestal temporário (período de janeiro a abril de 2008) em 15 unidades amostrais, com área de $1.000 \mathrm{~m}^{2}$ (dimensões de $20 \times 50 \mathrm{~m}$ ), distribuídas por todo o fragmento estudado. Nestas unidades, foram encontrados 2.026 indivíduos vivos, correspondendo a 2.265 fustes de 198 espécies arbóreas, distribuídas em 46 famílias.

Em cada unidade amostral, todos os indivíduos com dap $\geq 5 \mathrm{~cm}$ foram identificados pelo nome regional e científico. Além do dap (medido com trena), foram obtidas, com o hipsômetro digital Vertex IV, a altura dos fustes (hf) (início da copa) e a altura total (ht).

Ainda, em cada parcela, foram efetuadas as medidas das coordenadas plano-retangulares $(\mathrm{x}, \mathrm{y})$ da posição dos indivíduos na parcela.

A biomassa estocada no fuste de cada árvoreamostra foi determinada multiplicando-se os volumes de madeira e de casca pelas suas respectivas densidades. De posse dos estoques de biomassa e das medidas de diâmetro (dap) e alturas (fuste e total) das árvores-amostra, foram avaliados alguns modelos de regressão e as melhores equações foram utilizadas para estimar o estoque de biomassa do fuste dos indivíduos presentes nas parcelas do inventário.

Os resultados obtidos por Amaro (2010), a partir da equação que se ajustou melhor aos dados observados, são apresentados na Tabela 1 .

\subsubsection{Imagens digitais utilizadas}

Neste estudo, foram utilizadas imagens ortorretificadas do satélite IKONOS II, com resolução radiométrica de 11 bits e geométrica de $1 \mathrm{~m}$, adquiridas no ano de 2008, cobrindo a Bacia do Ribeirão São Bartolomeu, na qual está inserida a área de estudo. Inicialmente, os números digitais originais da área em que estão situadas as parcelas experimentais, nas bandas MS-1, MS-2, MS-3 e MS-4, foram convertidos em radiância espectral e,
Tabela 1. Estimativas de biomassa aérea feitas a partir do inventário florestal $\left(\mathrm{t} \mathrm{ha}^{-1}\right)$.

Table 1. Aerial biomass estimates from forest inventory $\left(\mathrm{t} \mathrm{ha}^{-1}\right)$.

\begin{tabular}{|cccc|}
\hline \multirow{2}{*}{ Parcelas } & \multicolumn{3}{c|}{ Variáveis Dependentes } \\
\cline { 2 - 4 } & Biom1 & Biom2 & Biom3 \\
\hline 1 & 243,99 & 243,99 & 254,49 \\
\hline 2 & 140,09 & 140,09 & 152,60 \\
\hline 3 & 127,08 & 127,08 & 137,24 \\
\hline 4 & 97,77 & 101,20 & 112,56 \\
\hline 5 & 135,85 & 145,88 & 161,85 \\
\hline 6 & 203,85 & 207,25 & 214,21 \\
\hline 7 & 401,34 & 401,34 & 418,49 \\
\hline 8 & 186,71 & 186,71 & 194,29 \\
\hline 9 & 159,82 & 168,52 & 176,97 \\
\hline 10 & 223,19 & 223,19 & 230,21 \\
\hline 11 & 179,26 & 218,33 & 225,00 \\
\hline 12 & 158,75 & 197,88 & 206,36 \\
\hline 13 & 136,32 & 171,97 & 179,46 \\
\hline 14 & 136,75 & 140,90 & 149,23 \\
\hline 15 & 291,63 & 291,63 & 303,60 \\
\hline
\end{tabular}

posteriormente, em reflectância planetária, de acordo com as equações apresentadas em Taylor (2009). Os valores de reflectância foram posteriormente utilizados na geração dos índices de vegetação.

\subsubsection{Limites das parcelas amostrais na ima- gem}

Para a obtenção da localização das parcelas na imagem Ikonos, foi efetuado um levantamento topográfico de precisão da posição de algumas árvores, em cada uma das parcelas, com a utilização de uma estação total Topcon GTS-102n.

O levantamento foi apoiado em pontos implantados na área e previamente ocupados com um receptor GPS ProMark2 (posicionamento estático com tempo de ocupação de, no mínimo, 30 minutos). As coordenadas geodésicas destes pontos de apoio foram obtidas a partir do processamento, no software Ashtech Solutions, dos arquivos coletados nos pontos com receptor ProMark2, utilizando-se como base o ponto da Rede Brasileira de Monitoramento Contínuo (RBMC), situada no campus da UFV.

A partir das coordenadas cartesianas (X, Y) das árvores da parcela, medidas por Amaro (2010), e das coordenadas com referência geodésica das mesmas, 
obtidas pelo levantamento topográfico por meio de procedimentos de rotação e translação, foi possível obter a localização e a orientação das parcelas na imagem, conforme mostrado no recorte da imagem Ikonos da Figura 2, o qual contempla todas as análises feitas a posteriori.

\subsubsection{Estimativas da biomassa aérea a partir das imagens Ikonos}

Para a avaliação do potencial das variáveis digitais, originárias de dados do sensor Ikonos, e que proporcionam as melhores estimativas da biomassa aérea, foram utilizadas análises estatísticas empregando Redes Neurais Artificiais (RNA).

Foram considerados, como variáveis dependentes, os dados de biomassa aérea obtidos por meio do inventário florestal e, como independentes, as variáveis digitais, obtidas a partir da imagem do satélite Ikonos (reflectância nas quatro bandas e os índices de vegetação: RVI, NDVI, TVI, SAVI, MSAVI, EVI, ARVI, GEMI, TCap1, TCap2, TCap3 e TCap4).

Durante a fase do inventário florestal, foram efetuadas, separadamente, estimativas dos estoques de biomassa aérea para os indivíduos arbóreos e não arbóreos, com diferentes variáveis dendrométricas (dap e altura do fuste). Desta forma, a variável dependente biomassa aérea foi subdividida em três grupos, de acordo com as variáveis dendrométricas utilizadas no inventário florestal. O objetivo desta subdivisão foi verificar eventuais influências da contribuição dos indivíduos, incluídas nestes grupos as estimativas dos estoques de biomassa aérea a partir dos dados oriundos do sensoriamento remoto.

As Tabelas 2 e 3 apresentam a identificação e a descrição das variáveis usadas nas análises.

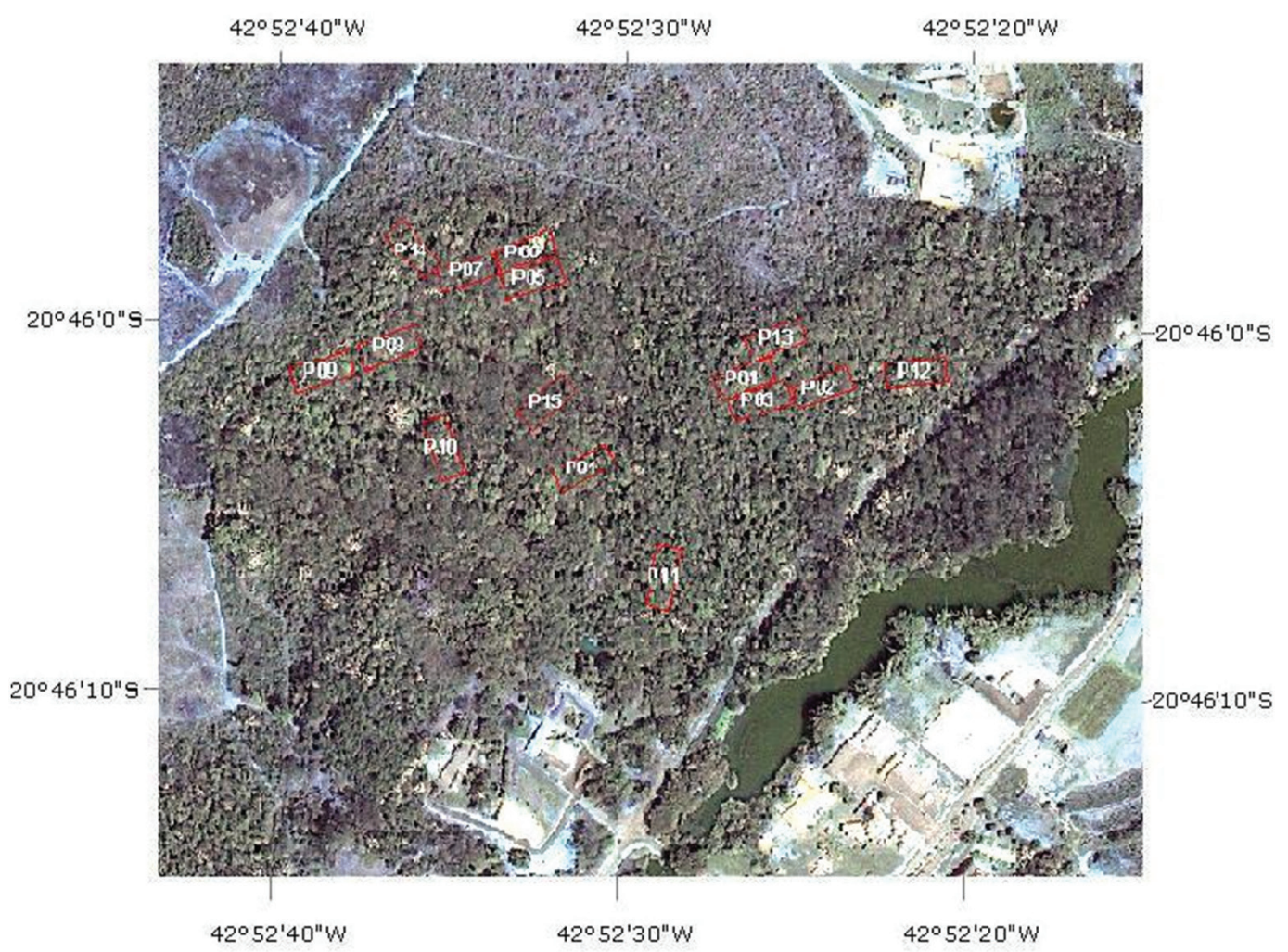

Sistema Geodésico WGS84

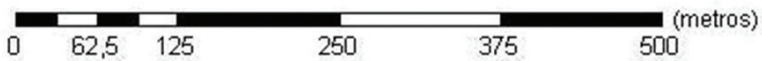

Figura 2. Localização das parcelas no fragmento estudado.

Figure 2. Sample units location in the fragment. 
Tabela 2. Variáveis dependentes.

Table 2. Dependent variables.

\section{Variável \\ Detalhes}

Biom1 Biomassa dos indivíduos vivos das parcelas com dap $\geq 5 \mathrm{~cm}$ (apenas os arbóreos)

Biom2 Biomassa dos indivíduos vivos das parcelas com dap $\geq 5 \mathrm{~cm}$ (arbóreos e não arbóreos)

Biom3 Biomassa dos indivíduos vivos das parcelas com dap $\geq 5 \mathrm{~cm}$ (arbóreos e não arbóreos) bem como aqueles com dap $<5 \mathrm{~cm}$ e altura do fuste maior ou menor do que $1,3 \mathrm{~m}$.

Tabela 3. Variáveis independentes.

Table 3. Independent variables.

\begin{tabular}{|cl}
\hline Variável & \multicolumn{1}{c}{ Descrição } \\
\hline Banda1 & Reflectância planetária na banda espectral 1 (azul) \\
\hline Banda2 & Reflectância planetária na banda espectral 2 (verde) \\
\hline Banda3 & Reflectância planetária na banda espectral 3 (vermelho) \\
\hline Banda4 & Reflectância planetária na banda espectral 4 (IV próximo) \\
\hline RVI & Índice de vegetação da razão \\
\hline NDVI & Índice de Vegetação da Diferença Normalizada (Normalized Difference Vegetation Index) \\
\hline TVI & Índice de vegetação transformado \\
\hline SAVI & Índice de vegetação ajustado ao solo \\
\hline MSAVI & índice de vegetação ajustado para a interferência do solo \\
\hline EVI & Índice de vegetação melhorado \\
\hline ARVI & Índice de vegetação com resistência atmosférica \\
\hline GEMI & Índice global de monitoramento ambiental \\
\hline TCap1 & Imagem transformada Tasseled Cap para a banda 1 \\
\hline TCap2 & Imagem transformada Tasseled Cap para a banda 2 \\
\hline TCap3 & Imagem transformada Tasseled Cap para a banda 3 \\
\hline TCap4 & Imagem transformada Tasseled Cap para a banda 4 \\
\hline
\end{tabular}

Na Tabela 1, são apresentados os dados do inventário florestal, de acordo com os grupos definidos na Tabela 2 .

$\mathrm{Na}$ Tabela 1, percebem-se nitidamente as influências da diversidade das espécies, da altura das árvores e do diâmetro dos fustes nos estoques de biomassa obtidos para a área de estudo. O estoque de biomassa total (Biom3) ultrapassa 400 t/ha na parcela 7, ao passo que, na parcela 4, é de 101,20 t/ ha, apesar de todas as parcelas terem a mesma área $\left(1.000 \mathrm{~m}^{2}\right)$.

Os valores médios da reflectância nas parcelas experimentais, nas quatro bandas espectrais da imagem do satélite IKONOS II, foram calculados pelo software ERDAS Imagine versão 10.0. Para este procedimento, foram utilizados polígonos AOI (area of interest), obtidos a partir das informações coletadas na fase do levantamento topográfico, referentes aos limites de cada uma das parcelas da área de estudo.
Com os valores médios da reflectância, foram calculados os valores dos índices de vegetação, para cada uma das parcelas.

Neste estudo, o treinamento das redes foi do tipo supervisionado, ou seja, a saída desejada foi fornecida à rede, que comparou o erro (diferença entre saída desejada e calculada) com a saída calculada. O erro foi informado à rede, que modificou seus parâmetros, a fim de minimizar o erro global e obter uma melhor solução. As redes foram treinadas para estimação dos valores de biomassa (variáveis Biom1, Biom2 e Biom3), a partir de três valores de variáveis de entradas diferentes, sendo:

- somente os valores das reflectâncias médias das parcelas experimentais nas quatro bandas espectrais (Banda1, Banda2, Banda3 e Banda4);

- valores médios obtidos para as parcelas experimentais dos índices RVI, NDVI, TVI, SAVI, MSAVI, EVI, ARVI, GEMI, TCap1, TCap2, TCap3 e TCap4; e 
- valores médios da reflectância nas quatro bandas e nas imagens índice de vegetação.

Foram treinadas 100 redes do tipo Perceptrons de Múltiplas Camadas (PMC), para cada combinação de valores de entrada. Das 100 RNA treinadas, selecionou-se apenas a melhor rede, em função do coeficiente de correlação entre valores observados e valores estimados pela RNA. A definição da arquitetura das redes, ou seja, o número de neurônios por camada e o número de camadas, foi otimizada pela ferramenta Intelligent Problem Solver (IPS), do software Statistica 10 (Statsoft Inc., 2011).

\section{RESULTADOS E DISCUSSÃO}

A Tabela 4 mostra as melhores configurações de redes testadas. Os resultados obtidos para as estimativas das variáveis dependentes Biom1, Biom2 e Biom3 são apresentados nas Tabelas 5, 6 e 7.
Análises das informações constantes da Tabela 5 mostram que os estoques de biomassa total (Biom3) foram estimados com um alto grau de exatidão pelas RNA's, com mínimas variações em relação aos valores estimados pelo inventário florestal, quando foram utilizadas apenas as quatro bandas do sensor Ikonos. Resultados similares foram obtidos quando se consideraram os estoques parciais de biomassa (Biom1 e Biom2).

Quando se utilizaram apenas os índices de vegetação, os resultados apresentados na Tabela 6 mostraram que os estoques de biomassa aérea foram muito próximos aos encontrados a partir da utilização das quatro bandas.

Os resultados apresentados na Tabela 7, quando se utilizaram todas as variáveis para alimentar a rede, também foram bastante eficientes e muito próximos dos dois métodos anteriores.

Tabela 4. Configurações das redes neurais artificiais testadas.

Table 4. Configurations of neural networks tested.

\begin{tabular}{ccccc} 
Entradas & $\begin{array}{c}\text { Número de Neurônios } \\
\text { na Camada Oculta }\end{array}$ & $\begin{array}{c}\text { Número de } \\
\text { Neurônios na Saída }\end{array}$ & $\begin{array}{c}\text { Função de Ativação da } \\
\text { Camada Oculta }\end{array}$ & $\begin{array}{c}\text { Função de Ativação da } \\
\text { Camada de Saída }\end{array}$ \\
\hline 1 & 12 & 6 & Tangente hiperbólica & Identidade \\
\hline 2 & 12 & 6 & Tangente hiperbólica & Identidade \\
\hline
\end{tabular}

Tabela 5. Estoques de biomassa estimados pelo inventário florestal e por RNA usando-se as quatro bandas espectrais como variáveis de entrada.

Table 5. Biomass stocks estimated by forest inventory and RNA using the four spectral bands as input variables.

\begin{tabular}{|c|c|c|c|c|c|c|c|c|c|}
\hline \multirow{3}{*}{ Parcelas } & \multicolumn{6}{|c|}{ Estoque de Biomassa das Parcelas ( $t / h a)$ - RNA: Bandas } & \multirow{2}{*}{\multicolumn{3}{|c|}{ Resíduos (t/ha) }} \\
\hline & \multicolumn{3}{|c|}{ Inventário } & \multicolumn{3}{|c|}{ Estimado } & & & \\
\hline & Biom 1 & Biom2 & Biom3 & Biom 1 & Biom2 & Biom3 & Biom 1 & Biom2 & Biom 3 \\
\hline 1 & 243,99 & 243,99 & 254,49 & 242,56 & 243,49 & 255,44 & $-1,43$ & $-0,50$ & 0,95 \\
\hline 2 & 140,09 & 140,09 & 152,60 & 139,19 & 139,51 & 150,65 & $-0,90$ & $-0,58$ & $-1,95$ \\
\hline 3 & 127,08 & 127,08 & 137,24 & 125,93 & 127,85 & 138,91 & $-1,15$ & 0,77 & 1,67 \\
\hline 4 & 97,77 & 101,20 & 112,56 & 97,81 & 101,69 & 112,93 & 0,04 & 0,49 & 0,37 \\
\hline 5 & 135,85 & 145,88 & 161,85 & 137,01 & 146,66 & 161,84 & 1,16 & 0,78 & $-0,01$ \\
\hline 6 & 203,85 & 207,25 & 214,21 & 204,00 & 207,27 & 214,57 & 0,15 & 0,02 & 0,36 \\
\hline 7 & 401,34 & 401,34 & 418,49 & 401,17 & 401,19 & 417,32 & $-0,17$ & $-0,15$ & $-1,17$ \\
\hline 8 & 186,71 & 186,71 & 194,29 & 186,65 & 186,66 & 193,96 & $-0,06$ & $-0,05$ & $-0,33$ \\
\hline 9 & 159,82 & 168,52 & 176,97 & 158,71 & 168,48 & 177,05 & $-1,11$ & $-0,04$ & 0,08 \\
\hline 10 & 223,19 & 223,19 & 230,21 & 222,25 & 222,58 & 230,36 & $-0,94$ & $-0,61$ & 0,15 \\
\hline 11 & 179,26 & 218,33 & 225,00 & 178,93 & 218,02 & 224,98 & $-0,33$ & $-0,31$ & $-0,02$ \\
\hline 12 & 158,75 & 197,88 & 206,36 & 161,10 & 197,78 & 205,10 & 2,35 & $-0,10$ & $-1,26$ \\
\hline 13 & 136,32 & 171,97 & 179,46 & 137,36 & 171,05 & 179,64 & 1,04 & $-0,92$ & 0,18 \\
\hline 14 & 136,75 & 140,90 & 149,23 & 138,22 & 141,92 & 149,47 & 1,47 & 1,02 & 0,24 \\
\hline 15 & 291,63 & 291,63 & 303,60 & 291,63 & 291,72 & 304,16 & 0,00 & 0,09 & 0,56 \\
\hline
\end{tabular}


Tabela 6. Estoques de biomassa estimados pelo inventário florestal e por RNA usando-se as imagens índices de vegetação como variáveis de entrada.

Table 6. Biomass stocks estimated by forest inventory and RNA using vegetation index images as input variables.

\begin{tabular}{|c|c|c|c|c|c|c|c|c|c|}
\hline \multirow{3}{*}{ Parcelas } & \multicolumn{6}{|c|}{ Estoque de Biomassa das Parcelas (t/ha) - RNA: Índices de Vegetação } & \multirow{2}{*}{\multicolumn{3}{|c|}{ Resíduos (t/ha) }} \\
\hline & \multicolumn{3}{|c|}{ Inventário } & \multicolumn{3}{|c|}{ Estimado - Índices } & & & \\
\hline & Biom 1 & Biom2 & Biom3 & Biom 1 & Biom2 & Biom3 & Biom 1 & Biom2 & Biom3 \\
\hline 1 & 243,99 & 243,99 & 254,49 & 244,05 & 244,01 & 254,57 & 0,06 & 0,02 & 0,08 \\
\hline 2 & 140,09 & 140,09 & 152,60 & 139,84 & 141,05 & 151,07 & $-0,25$ & 0,96 & $-1,53$ \\
\hline 3 & 127,08 & 127,08 & 137,24 & 126,86 & 126,72 & 137,30 & $-0,22$ & $-0,36$ & 0,05 \\
\hline 4 & 97,77 & 101,20 & 112,56 & 97,98 & 101,31 & 112,84 & 0,21 & 0,11 & 0,27 \\
\hline 5 & 135,85 & 145,88 & 161,85 & 135,85 & 145,88 & 161,85 & 0,00 & 0,00 & 0,00 \\
\hline 6 & 203,85 & 207,25 & 214,21 & 203,81 & 207,29 & 214,23 & $-0,04$ & 0,04 & 0,02 \\
\hline 7 & 401,34 & 401,34 & 418,49 & 401,34 & 401,34 & 418,49 & 0,00 & 0,00 & 0,00 \\
\hline 8 & 186,71 & 186,71 & 194,29 & 186,75 & 186,68 & 194,27 & 0,04 & $-0,03$ & $-0,02$ \\
\hline 9 & 159,82 & 168,52 & 176,97 & 159,60 & 168,15 & 176,83 & $-0,22$ & $-0,37$ & $-0,14$ \\
\hline 10 & 223,19 & 223,19 & 230,21 & 223,33 & 223,28 & 230,39 & 0,13 & 0,09 & 0,18 \\
\hline 11 & 179,26 & 218,33 & 225,00 & 179,20 & 218,25 & 224,98 & $-0,06$ & $-0,08$ & $-0,02$ \\
\hline 12 & 158,75 & 197,88 & 206,36 & 158,63 & 197,86 & 206,17 & $-0,12$ & $-0,02$ & $-0,19$ \\
\hline 13 & 136,32 & 171,97 & 179,46 & 136,53 & 172,17 & 179,65 & 0,21 & 0,20 & 0,19 \\
\hline 14 & 136,75 & 140,90 & 149,23 & 137,01 & 140,36 & 150,34 & 0,26 & $-0,54$ & 1,11 \\
\hline 15 & 291,63 & 291,63 & 303,60 & 291,62 & 291,63 & 303,59 & $-0,01$ & 0,00 & $-0,01$ \\
\hline
\end{tabular}

Tabela 7. Estoques de biomassa estimados pelo inventário florestal e por RNA, usando-se as bandas espectrais e as imagens índices de vegetação como variáveis de entrada.

Table 7. Biomass stocks estimated by forest inventory and RNA using the four spectral bands and vegetation index images as input variables.

\begin{tabular}{|c|c|c|c|c|c|c|c|c|c|}
\hline \multirow{3}{*}{ Parcelas } & \multicolumn{6}{|c|}{ Estoque de Biomassa das Parcelas (t/ha) - RNA: Bandas e Índices } & \multirow{2}{*}{\multicolumn{3}{|c|}{ Resíduos (t/ha) }} \\
\hline & \multicolumn{3}{|c|}{ Inventário } & \multicolumn{3}{|c|}{ Estimado - Índices } & & & \\
\hline & Biom1 & Biom2 & Biom3 & Biom1 & Biom2 & Biom3 & Biom1 & Biom2 & Biom3 \\
\hline 1 & 243,99 & 243,99 & 254,49 & 243,98 & 243,98 & 254,48 & $-0,01$ & $-0,01$ & $-0,01$ \\
\hline 2 & 140,09 & 140,09 & 152,60 & 140,10 & 140,09 & 152,62 & 0,01 & 0,00 & 0,02 \\
\hline 3 & 127,08 & 127,08 & 137,24 & 127,04 & 127,09 & 137,25 & $-0,04$ & 0,01 & 0,01 \\
\hline 4 & 97,77 & 101,20 & 112,56 & 97,72 & 101,15 & 112,51 & $-0,05$ & $-0,05$ & $-0,05$ \\
\hline 5 & 135,85 & 145,88 & 161,85 & 135,86 & 145,88 & 161,86 & 0,01 & 0,00 & 0,01 \\
\hline 6 & 203,85 & 207,25 & 214,21 & 203,83 & 207,25 & 214,21 & $-0,02$ & 0,00 & 0,00 \\
\hline 7 & 401,34 & 401,34 & 418,49 & 401,34 & 401,34 & 418,49 & 0,00 & 0,00 & 0,00 \\
\hline 8 & 186,71 & 186,71 & 194,29 & 186,69 & 186,69 & 194,27 & $-0,02$ & $-0,02$ & $-0,02$ \\
\hline 9 & 159,82 & 168,52 & 176,97 & 159,85 & 168,52 & 176,96 & 0,03 & 0,00 & $-0,01$ \\
\hline 10 & 223,19 & 223,19 & 230,21 & 223,20 & 223,18 & 230,21 & 0,01 & $-0,01$ & 0,00 \\
\hline 11 & 179,26 & 218,33 & 225,00 & 179,24 & 218,32 & 224,98 & $-0,02$ & $-0,01$ & $-0,02$ \\
\hline 12 & 158,75 & 197,88 & 206,36 & 158,79 & 197,92 & 206,40 & 0,04 & 0,04 & 0,04 \\
\hline 13 & 136,32 & 171,97 & 179,46 & 136,29 & 171,94 & 179,43 & $-0,03$ & $-0,03$ & $-0,03$ \\
\hline 14 & 136,75 & 140,90 & 149,23 & 136,84 & 140,98 & 149,29 & 0,09 & 0,08 & 0,06 \\
\hline 15 & 291,63 & 291,63 & 303,60 & 291,63 & 291,63 & 303,60 & 0,00 & 0,00 & 0,00 \\
\hline
\end{tabular}

A Tabela 8 e a Figura 3 apresentam os resíduos percentuais para as três situações utilizadas como variáveis de entrada, para as estimativas da biomassa aérea total (Biom3) nas 15 parcelas experimentais.
A análise da Tabela 8 e da Figura 3 mostra que os resíduos em percentagem variaram de $-1,275$ a +1,215; -1,003 a +0,742 e $-0,045$ a $+0,043$, respectivamente, quando se utilizaram as quatro 
Tabela 8. Resíduos das estimativas da biomassa total por RNA.

Table 8. Estimate residuals of the total biomass from RNA.

\begin{tabular}{|c|c|c|c|c|c|c|c|}
\hline \multicolumn{8}{|c|}{ Biomassa Total por Redes Neurais Artificiais } \\
\hline \multirow[b]{2}{*}{ Parcelas } & \multirow[b]{2}{*}{ Inventário } & \multirow{2}{*}{$\begin{array}{c}\text { Bandas } \\
(1 \text { a } 4)\end{array}$} & \multirow[b]{2}{*}{ Îndices } & \multirow{2}{*}{$\begin{array}{c}\text { Bandas e } \\
\text { índices }\end{array}$} & \multicolumn{3}{|c|}{ Resíduos (\%) } \\
\hline & & & & & f (Bandas) & f (Îndices) & $\begin{array}{c}\text { f (Bandas e } \\
\text { Índices) }\end{array}$ \\
\hline 1 & 254,490 & 255,441 & 254,573 & 254,480 & 0,374 & 0,033 & $-0,004$ \\
\hline 2 & 152,600 & 150,654 & 151,069 & 152,616 & $-1,275$ & $-1,003$ & 0,010 \\
\hline 3 & 137,240 & 138,908 & 137,295 & 137,246 & 1,215 & 0,040 & 0,005 \\
\hline 4 & 112,560 & 112,931 & 112,835 & 112,510 & 0,330 & 0,245 & $-0,045$ \\
\hline 5 & 161,850 & 161,839 & 161,850 & 161,856 & $-0,007$ & 0,000 & 0,004 \\
\hline 6 & 214,210 & 214,573 & 214,228 & 214,208 & 0,170 & 0,008 & $-0,001$ \\
\hline 7 & 418,490 & 417,320 & 418,490 & 418,490 & $-0,280$ & 0,000 & 0,000 \\
\hline 8 & 194,290 & 193,964 & 194,266 & 194,271 & $-0,168$ & $-0,012$ & $-0,010$ \\
\hline 9 & 176,970 & 177,051 & 176,831 & 176,963 & 0,046 & $-0,078$ & $-0,004$ \\
\hline 10 & 230,210 & 230,362 & 230,394 & 230,213 & 0,066 & 0,080 & 0,001 \\
\hline 11 & 225,000 & 224,978 & 224,980 & 224,984 & $-0,010$ & $-0,009$ & $-0,007$ \\
\hline 12 & 206,360 & 205,096 & 206,168 & 206,397 & $-0,613$ & $-0,093$ & 0,018 \\
\hline 13 & 179,460 & 179,637 & 179,649 & 179,434 & 0,099 & 0,105 & $-0,015$ \\
\hline 14 & 149,230 & 149,465 & 150,337 & 149,294 & 0,157 & 0,742 & 0,043 \\
\hline 15 & 303,600 & 304,156 & 303,594 & 303,600 & 0,183 & $-0,002$ & 0,000 \\
\hline
\end{tabular}

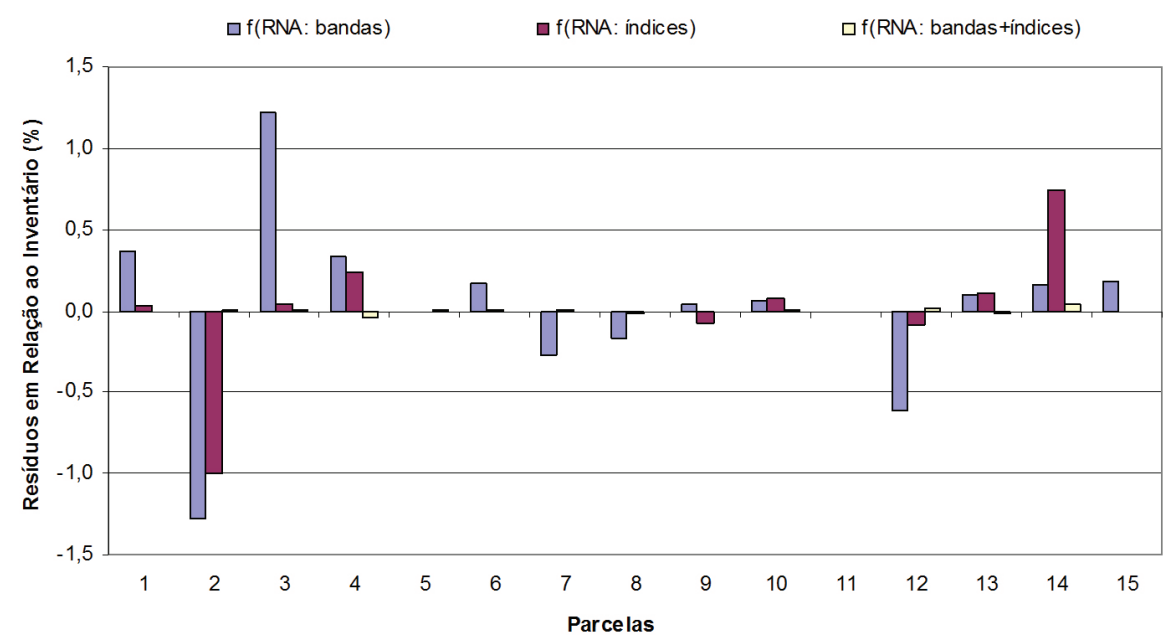

Figura 3. Resíduos percentuais da biomassa total obtidos por meio de RNA.

Figure 3. Residuals in percentage of the total biomass estimated from RNA.

bandas, os índices de vegetação e a combinação das bandas e os índices de vegetação, como entrada para alimentar a rede.

Com base nos resultados apresentados, verificase que, para o caso da área estudada, apenas as bandas 1, 2, 3 e 4 podem ser utilizadas como variáveis de entrada, uma vez que se mostraram eficientes para estimar a biomassa total (Biom3), embora os resíduos tenham sido ainda menores quando foram utilizadas as bandas e os índices de vegetação.

Schoeninger et al. (2008a) usaram RNAs para estimar biomassa em uma Floresta Ombrófila Densa, no Estado de Santa Catarina, a partir das quatro bandas do sensor IKONOS. Os resultados mostraram que as diferenças entre a biomassa estimada pelo inventário e a estimada pela rede apresentaram erros 
que variaram de 1,05 a $8,18 \%$ e um erro percentual médio de $3,73 \%$.

Schoeninger (2006) desenvolveu um trabalho com o objetivo de elaborar mapas temáticos para estimativas de biomassa e carbono orgânico armazenado no componente arbóreo de uma Floresta Ombrófila Densa, localizada nos municípios de Apiúna e Presidente Nereu, no Estado de Santa Catarina. Na pesquisa, foi verificado o desempenho de RNA e equações de regressão linear na predição das variáveis biomassa arbórea e carbono arbóreo. Resultados mostraram que as estimativas de biomassa arbórea e carbono, com a utilização da metodologia de RNA, foram superiores àquelas obtidas com as técnicas de regressão linear. Os melhores resultados com o emprego de RNA apresentaram um erro percentual médio, em relação às amostras de verificação, de 3,73\% para a biomassa e de $3,59 \%$ para o carbono, enquanto a melhor equação de regressão linear apresentou erros padrão da estimativa da ordem de $29,8 \%$.

Foody et al. (2001) estimaram a biomassa de florestas tropicais no nordeste de Bornéu, utilizando imagens do Landsat 5 TM. No trabalho, as abordagens convencionais utilizadas na estimativa de biomassa florestal, a partir de dados de sensoriamento remoto, foram avaliadas com a aplicação da metodologia da RNA, técnica que mostrou ser adequada para a estimativa de biomassa, uma vez que as estimativas obtidas apresentaram-se fortemente correlacionadas com os dados de inventário florestal $(\mathrm{r}=0,80)$.

\section{CONCLUSÕES}

- A técnica das redes neurais artificiais apresentou um excelente desempenho nas estimativas dos estoques de biomassa aérea em um fragmento de mata natural, através de imagens do satélite IKONOS.

- Para as condições da área de estudo, verificou-se que o emprego da técnica de RNA com apenas as bandas 1, 2, 3 e 4 do satélite IKONOS como variáveis de entrada foi eficiente para estimar a biomassa aérea total, embora os resíduos tenham sido ainda menores quando utiizaram-se as quatro bandas e os 12 índices de vegetação.

\section{RECOMENDAÇÕES}

Para futuros trabalhos, recomenda-se trabalhar com um maior número de amostras, bem como coletar dados em diferentes estações do ano, haja vista que muitas das espécies são caducifólias, perdendo suas folhas durante a estação seca, fato que aconteceu durante o desenvolvimento deste trabalho. Recomenda-se também testar diferentes configurações de redes neurais, de forma a conseguir uma maior correlação entre os dados dendrométricos e digitais.

\section{STATUS DA SUBMISSÃO}

Recebido: 17 jul., 2013

Aceito: 29 mar., 2014

Publicado: 28 ago., 2014

\section{AUTOR(ES) PARA CORRESPONDÊNCIA}

Vicente Paulo Soares

Departamento de Engenharia Florestal, Universidade Federal de Viçosa - UFV, CEP 36570-000, Viçosa, MG, Brasil

e-mail: vicente@ufv.br

\section{REFERÊNCIAS}

Amaro MA. Quantificação do estoque volumétrico, de biomassa e de carbono em uma floresta estacional semidecidual no município de Viçosa-MG. [tese]. Viçosa: Universidade Federal de Viçosa; 2010.

Embrapa. Serviço Nacional de Levantamento e Conservação de Solos. Sistema Brasileiro de Classificação de Solos. Rio de Janeiro: Embrapa; 2006.

Ferraz AS. Estimação dos estoques de biomassa e carbono na parte aérea de um fragmento de floresta estacional semidecidual por meio de imagens de satélite Ikonos II. [tese]. Viçosa: Universidade Federal de Viçosa; 2012.

Flores EJM. Potencial produtivo e alternativas de manejo sustentável de um fragmento de Mata Atlântica secundária, município de Viçosa, Minas Gerais [dissertação]. Viçosa: Universidade Federal de Viçosa; 1993.

Foody GM, Cutler ME, Mcmorrow J, Pelz D, Tangki H, Boyd DS et al. Mapping the biomass of Bornean tropical rain forest from remotely sensed data. Global Ecology \& Biogeography 2001; 10: 379-387. http://dx.doi. org/10.1046/j.1466-822X.2001.00248.x 
Higuchi N, Carvalho Júnior JA. Fitomassa e conteúdo de carbono de espécies arbóreas da Amazônia. In: Seminário Emissão $x$ Seqüestro de $\mathrm{Co}_{2}$ - uma nova Oportunidade de Negócios para o Brasil, 1994; Rio de Janeiro. Rio de Janeiro: CVRD; 1994. p. 125-145.

Rezende SB. Estudo de crono-toposequência em Viçosa$M G$. [Dissertação]. Viçosa: Universidade Federal de Viçosa; 1971.

Romanovski Z. Morfologia e aspectos hidrológicos da microbacia Rua Nova, Viçosa-MG, para fins de manejo [tese]. Viçosa: Universidade Federal de Viçosa; 2001.

Schoeninger ER, Koehler HS, Botelho MF, Watzlawick LC, Oliveira Filho PC. Uso de Redes Neurais artificiais para mapeamento de biomassa e carbono orgânico no componente arbóreo de uma floresta ombrófila densa. Ambiência - Revista do Setor de Ciências Agrárias e Ambientais 2008a; 4(2): 175-195.

Schoeninger ER, Koehler HS, Watzlawick LC, Oliveira Filho PC. Uso de redes neurais artificiais como uma alternativa para mapeamento de biomassa e carbono orgânico no componente arbóreo de florestas naturais. Ambiência - Revista do Setor de Ciências Agrárias e Ambientais 2008b; 4(3): 529-549.

Schoeninger ER. Uso de redes neurais artificiais para o mapeamento de biomassa e carbono orgânico no componente arbóreo de uma floresta ombrófila densa. [tese]. Curitiba: Universidade Federal do Paraná, 2006. PMid:16941603.
Silveira P, Koehler HS, Sanquetta CR, Arce JE. O estado da arte na estimativa de biomassa e carbono em formações florestais. Floresta 2008; 38(1): 185-206.

Somogyi Z, Cienciala E, Makipaa R, Muukkonen $\mathrm{P}$, Lehtonen A, Weiss P. Indirect methods of largescale forest biomass estimation. European Journal of Forest Research 2006; 126(2):197-207. http://dx.doi. org/10.1007/s10342-006-0125-7

Souza CL, Ponzoni FJ. Avaliação de índices de vegetação e de bandas TM/Landsat para estimativa de volume de madeira em floresta implantada de Pinus spp. In: Anais do Simpósio Brasileiro de Sensoriamento Remoto, 1988, Santos. São José dos Campos: INPE; 1998. p. 1549-1560.

Statsoft Inc. Statistica (data analysis software system). version 10. [cited 2011 Mar 5]. Available from: http:// www.statsoft.com.

Taylor M. IKONOS planetary reflectance and mean solar exoatmospheric irradiance. GeoEye - IKONOS Planetary Reflectance; 2009. QSOL Rev. 2. 3 p.

Watzlawick LF, Kirchner FF, Sanguetta CR. Estimativa de biomassa e carbono em floresta com araucária utilizando imagens do satélite IKONOS II. Ciência Florestal 2009; 19(2): 169-181.

Watzlawick LF. Estimativa de biomassa e carbono em floresta ombrófila mista e plantações florestais a partir de dados de imagens do satélite IKONOS II [tese]. Curitiba: Universidade Federal do Paraná; 2003. 